\title{
Preference for a prefilled syringe or an auto- injection device for delivering golimumab in patients with moderate-to-severe ulcerative colitis: a randomized crossover study
}

This article was published in the following Dove Press journal:

Patient Preference and Adherence

\author{
Séverine Vermeire,' \\ François D'heygere, ${ }^{2}$ \\ Antoine Nakad, ${ }^{3}$ Denis \\ Franchimont, ${ }^{4}$ Fernand \\ Fontaine,$^{5}$ Edouard Louis, ${ }^{6}$ \\ Philippe Van Hootegem, ${ }^{7}$ \\ Olivier Dewit, ${ }^{8}$ Guy \\ Lambrecht, ${ }^{9}$ Beatrijs \\ Strubbe, ${ }^{10}$ Filip Baert 11 \\ 'Department of Gastroenterology, \\ University Hospital Gasthuisberg, \\ Leuven, Belgium; ${ }^{2}$ Department of \\ Gastroenterology, AZ Groeninge, \\ Kortrijk, Belgium; ${ }^{3}$ Department \\ of Gastroenterology, CHWAPI, \\ Tournai, Belgium; ${ }^{4}$ Department of \\ Gastroenterology, Erasme Hospital, \\ Brussels, Belgium; ${ }^{5}$ Department of \\ Gastroenterology, CHC St Joseph, \\ Liège, Belgium; ${ }^{6}$ Department of \\ Gastroenterology, University Hospital \\ CHU Sart Tilman, Liège, Belgium; \\ ${ }^{7}$ Department of Gastroenterology, \\ AZ St Lucas, Brugge, Belgium; \\ ${ }^{8}$ Department of Gastroenterology, \\ UCL St Luc, Brussels, Belgium; \\ 'Department of Gastroenterology, \\ AZ Damiaan, Oostende, Belgium; \\ ${ }^{10}$ Department of Gastroenterology, \\ OLV Hospital, Aalst, Belgium; \\ "Department of Gastroenterology, \\ AZ Delta, Roeselare-Menen, Belgium
}

Correspondence: Séverine Vermeire Department of Gastroenterology, University Hospitals Leuven, Herestraat 49, 3000 Leuven, Belgium Tel +3216344218 Fax +32 I6 344419

Email severine.vermeire@uzleuven.be
Purpose: Simponi ${ }^{\circledR}$ (golimumab, MSD) is a fully human monoclonal antibody against tumor necrosis factor alpha administered subcutaneously using an autoinjector or a prefilled syringe. This study examined preference for administration of golimumab by autoinjector or prefilled syringe in patients with moderate-to-severe ulcerative colitis (UC).

Patients and methods: This was a multicenter, open-label, randomized crossover trial (EudraCT no 2014-000656-29). Patients with moderate-to-severe UC were randomized 1:1 to receive 2 subcutaneous injections of $50 \mathrm{mg}$ golimumab with the autoinjector followed by 2 injections of $50 \mathrm{mg}$ with the prefilled syringe or the same 4 injections administered in the opposite order. Patients assessed preference, ease of use, and discomfort immediately after the injections and 2 weeks later.

Results: Ninety-one patients were included (median age=42.7 years [range, 19.7-93.7]; 58\% male). The autoinjector was preferred by $76.9 \%$ of patients immediately after injections and by $71.4 \%$ 2 weeks later. The autoinjector was more often considered extremely easy or easy to use $(94.5 \%)$ than the prefilled syringe (73.6\%). Moderate discomfort or worse was reported by more patients when using the prefilled syringe (20.9\%) than when using the autoinjector $(5.5 \%)$, and severe discomfort or discomfort preventing injection of future doses was reported by $8.8 \%$ for the prefilled syringe but not at all when using the autoinjector. A favorable or extremely favorable overall impression was reported by $89.0 \%$ for the autoinjector and $72.5 \%$ for the prefilled syringe.

Conclusion: Most patients with moderate-to-severe UC preferred to self-administer golimumab with the autoinjector over a prefilled syringe.

Keywords: autoinjector, adherence, anti-TNF, subcutaneous injection, treatment, selfinjection

\section{Introduction}

Ulcerative colitis (UC) is a chronic and incurable autoimmune inflammatory bowel disorder characterized by continuous inflammation and ulceration of the mucosa of the rectum and, to a variable extent, the colon. ${ }^{1,2}$ The disease affects 2.5 million people worldwide and is usually diagnosed when individuals are in their 20 s and peaks again in their 60 s or 70 s, but it can occur at any age. UC is generally characterized by flares that alternate with periods of remission, although some patients have continuous activity. The severity of flares and their response to treatment are difficult to predict, although the frequency of flares decreases with time. Between $25 \%$ and $40 \%$ of people living with UC will require surgery at some point in their life. ${ }^{1}$ 


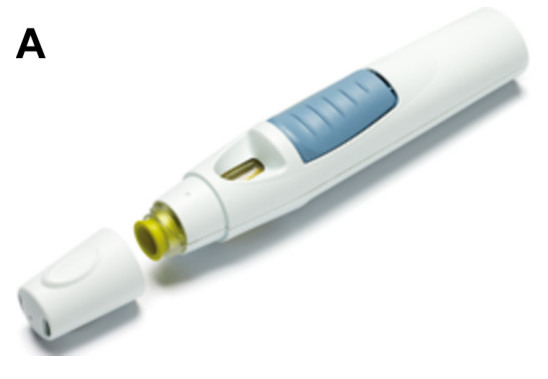

Figure I Golimumab injection devices.

Notes: (A) Smartject autoinjector. (B) Prefilled syringe.

Simponi ${ }^{\circledR}$ (golimumab, MSD, Janssen Biotech, Inc., Horsham, PA, USA) is a fully human monoclonal antibody against tumor necrosis factor $\alpha$ (TNF- $\alpha$ ) available in the European Union since 2013 for the treatment of moderateto-severe active UC in adult patients who have had an inadequate response to conventional therapy or who are intolerant to or have medical contraindications for such therapies. ${ }^{3}$ Golimumab is also indicated for the treatment of moderate-to-severe active rheumatoid arthritis (RA) (in combination with methotrexate), active psoriatic arthritis (alone or in combination with methotrexate), and active ankylosing spondylitis.

Golimumab is administered with the SmartJect ${ }^{\circledR}$ autoinjector (MSD, Janssen Biotech, Inc.) or with a prefilled syringe (Figure 1). The SmartJect autoinjector was developed to simplify self-injection of golimumab for patients suffering from RA, psoriatic arthritis, and ankylosing spondylitis, with the objective of optimizing treatment adherence. ${ }^{4}$ Autoinjectors offer several advantages, including portability, convenience, and flexible scheduling, and they have been shown to improve treatment adherence..$^{5-7}$ In the GO-MORE study, which examined the efficacy and safety of golimumab in biologic-naive RA patients, two-thirds of those who self-injected chose to use the autoinjector over a prefilled syringe. ${ }^{4}$ In addition, most of the patients using the autoinjector had a favorable impression of it, considered it easy to use, and reported that it caused little pain or discomfort. Device preferences for UC patients, however, have not been reported and may be different from RA patients who often suffer from hand pain, swelling, and deformities. Here, we report the results of a study examining whether patients with moderate-to-severe UC prefer administration of golimumab using the SmartJect autoinjector or a prefilled syringe.

\section{Patients and methods Study design}

This was a multicenter, open-label, randomized, crossover trial comparing preference for administration of golimumab
B

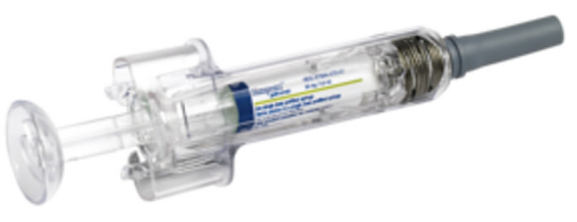

using the SmartJect autoinjector or a prefilled syringe in patients with moderate-to-severe UC (EudraCT no 2014000656-29). The trial was conducted at 20 sites in Belgium (19 sites recruited patients) between July 2014 and October 2015. The primary objective was to determine whether UC patients prefer to administer golimumab using the autoinjector, using a prefilled syringe, or are undecided. Secondary objectives were to determine which of the 2 administration devices patients consider the easiest to use and result in the least discomfort, and how patient characteristics influence device preference.

The study included adults with an established diagnosis of UC and moderate-to-severe disease (Mayo score $\geq 6$, including an endoscopic subscore $\geq 2$ ) and a previous conventional therapy of at least 3 months with aminosalicylates and at least 3 months with corticosteroids, 6-mercaptopurine, or azathioprine unless intolerant to or contraindicated for such therapies. Individuals who previously self-injected any agent or who were using other biological agents were excluded.

Patients completed a questionnaire to collect demographic data, and investigators collected information about the patient's medical history. Patients were then randomized $1: 1$ to receive 2 injections of golimumab $50 \mathrm{mg}$ (Simponi ${ }^{\circledR}$, MSD) with the autoinjector (SmartJect ${ }^{\circledR}, \mathrm{MSD}$ ) followed by 2 injections of $50 \mathrm{mg}$ with the prefilled syringe or 2 injections of $50 \mathrm{mg}$ golimumab with the prefilled syringe followed by 2 injections with the autoinjector (total $200 \mathrm{mg}$ golimumab administered). All injections were subcutaneous, were in the same part of the body, and were performed on the same day (day 0). The first of the 2 injections with each device was performed by the physician, and the second by the patient under the physician's supervision.

Immediately after using each device, patients answered a questionnaire assessing the hand used to self-inject (left, right, both), ease of use for self-injection (extremely easy, easy, neither easy nor difficult, difficult, or extremely difficult), overall discomfort (none, mild, moderate, severe, 
or such discomfort that I cannot inject future doses), and overall impression of the self-injection experience (extremely favorable, favorable, neither favorable nor unfavorable, unfavorable, or extremely unfavorable). After completing all 4 injections, patients completed a questionnaire on their preference for the devices (prefilled syringe, autoinjector, or undecided). After 2 weeks, the patient was contacted to complete the device preference questionnaire again to capture the effect of any delayed adverse events on the patient's responses.

Investigators recorded adverse events according to the International Conference on Harmonization Guidelines for Good Clinical Practice including the following: adverse event/diagnosis; dates of onset and resolution; severity (mild, moderate, severe), whether the event was serious (yes/no) and, if so, why; potential relationship to the study drug (yes/no); and action taken. Adverse events were considered serious if they resulted in death, were life threatening, required hospitalization or prolongation of an existing inpatient hospitalization, resulted in a persistent or significant disability or incapacity, were a congenital abnormality or birth defect, were cancer, were associated with an overdose, or were any other important medical event.

\section{Ethics}

The study was approved by each site's independent ethics committee (Table S1) and was conducted in accordance with International Conference on Harmonization Guideline for Good Clinical Practice. All included patients provided written informed consent.

\section{Study size estimate}

A power calculation was not performed. Instead, a study size estimate of 100 subjects was planned based on sample sizes that yielded relevant results in similar studies. ${ }^{8-11}$ Assuming 10\% dropout, approximately 110 subjects were to be screened.

\section{Statistical analysis}

The primary outcome measure (device preference) was analyzed in the per-protocol set, defined as all subjects who met the inclusion and exclusion criteria, received all 4 injections, and completed the device preference questionnaire. Statistical analyses of preference included frequency distribution overall immediately and 2 weeks after injection; by order of device administration; 2 weeks after injection by preference immediately after injection; and by age, sex, ethnicity, marital status, education level, employment status, and total Mayo score category. Statistical analysis of secondary outcome measures (ease of use, discomfort, and overall impression) included frequency distribution overall and by order of injection. As stipulated in the study protocol, only descriptive statistics were calculated, although in a post hoc analysis, preferences were analyzed according to subject baseline characteristics by Cochrane-Armitage trend test or Fisher's exact test, with $p$-values below 0.05 considered to indicate statistical significance. Missing data were not replaced. Calculations were made using SAS version 9.2 (SAS Institute, Cary, NC, USA).

\section{Results \\ Patients}

Between July 11, 2014, and September 17, 2015, 100 patients were included in the study, and the study was completed on October 5, 2015. Of the 100 recruited patients, 99 were treated. Another 8 patients did not fulfill the selection criteria. Thus, 91 patients were included in the analysis. Most of these patients were between 30 and 60 years of age, slightly more than half were male, and all but 2 were White/Caucasian (Table S2). On average, patients had been diagnosed with UC for 8.6 years. Disease severity was moderate in about two-thirds and severe in about one-third, although precise proportions depended slightly on the assessment (Mayo score, physician's global assessment, and sigmoidoscopic and endoscopic findings). Most were being treated with 5-aminosalicylic acid and corticosteroids, and most had not previously received anti-TNF therapy.

\section{Device preference}

Immediately after injections, approximately three-quarters of patients $(76.9 \%)$ indicated that they preferred administering golimumab with the autoinjector (Figure 2). This was similar to the preference reported 2 weeks later, with $71.4 \%$ reporting that they preferred the autoinjector. This was also the case irrespective of the order of injection, although more patients who started with the autoinjector preferred it $(84.4 \%)$ than patients who started with the prefilled syringe (69.6\%). Also, most patients $(92.3 \%)$ did not change their preference 2 weeks later: of those who preferred a prefilled syringe immediately after the injections, all still preferred it 2 weeks later, and of those that preferred the autoinjector immediately after the injections, 92.9\% still preferred it 2 weeks later. Results were similar when analyzed for all 99 patients completing the questionnaire (data not shown). A post hoc analysis showed that preference for the autoinjector was not significantly affected by patient age, disease 
A

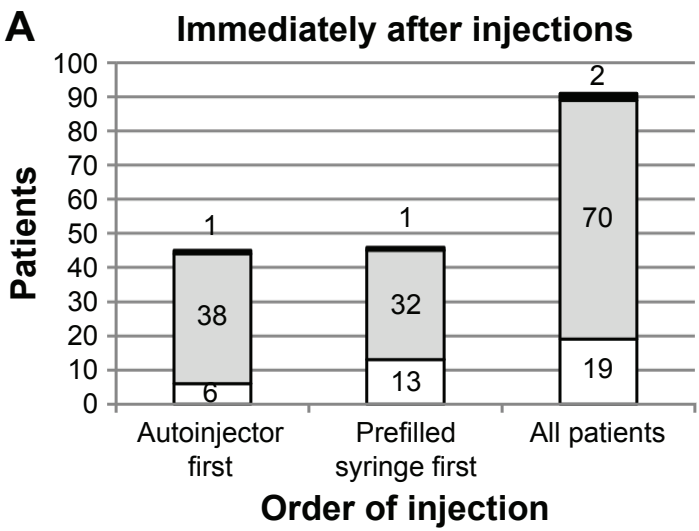

C Preference at week 2 according to preference immediately after

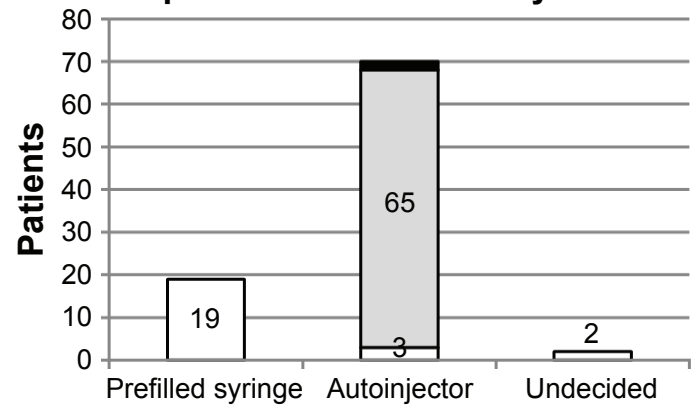

Preference at week 0
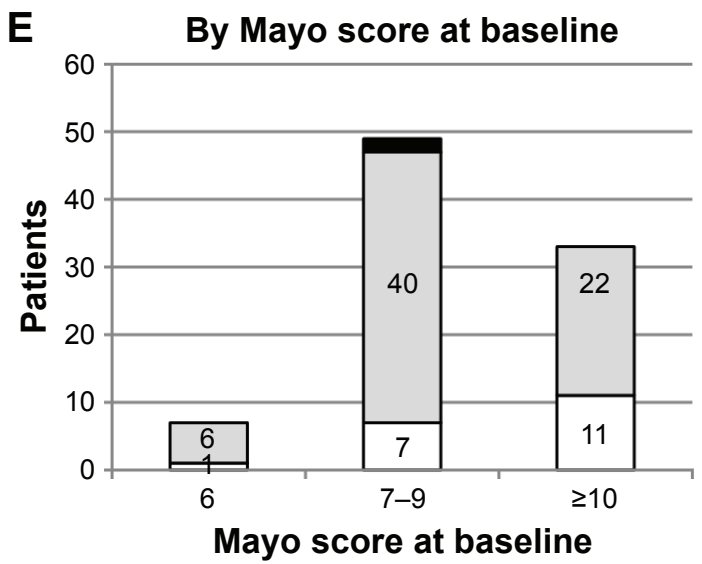

B

2 weeks after injections

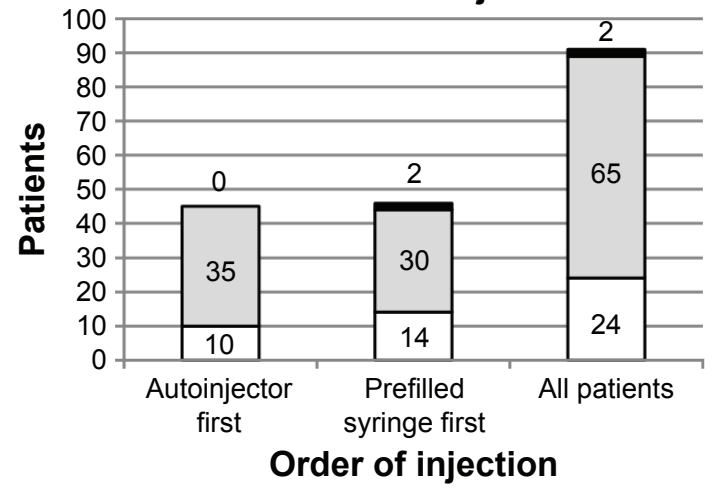

D

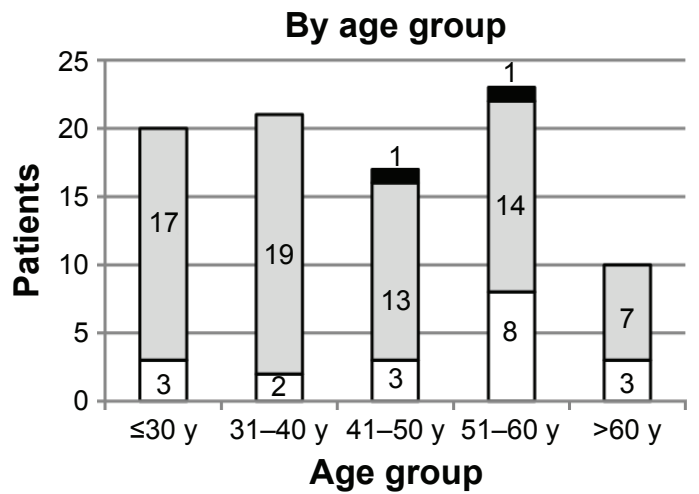

Age group
Undecided

Preferred autoinjector

$\square$ Preferred prefilled syringe

Figure 2 Device preference.

Notes: Patient preference for the different devices was assessed immediately after the injections and 2 weeks later. (A) Device preference according to order of presentation immediately after the injections. (B) Device preference according to order of presentation 2 weeks after the injections. (C) Device preference at week 2 according to preference immediately after the injections. (D) Device preference immediately after the injections according to age group. (E) Device preference immediately after the injections according to Mayo score at baseline.

severity as measured by the total Mayo score, sex, marital/ cohabitation status, level of education, employment status, or time since UC diagnosis (data not shown).

\section{Ease of use, discomfort, and overall impression of the devices}

More patients considered the autoinjector extremely easy or easy to use $(94.5 \%)$ than the prefilled syringe $(73.6 \%)$ (Table 1). Moderate discomfort or worse was reported by only 5 patients $(5.5 \%)$ when using the autoinjector but by 19 patients $(20.9 \%)$ when using the prefilled syringe. Severe discomfort or discomfort such that the patient could not inject future doses was reported by 8 patients $(8.8 \%)$ when using the prefilled syringe but was not reported by any of the patients using the autoinjector.

In agreement with these findings, $89.0 \%$ of patients had an overall extremely favorable or favorable impression of the autoinjector, while $72.5 \%$ had an extremely favorable or 
Table I Ease of use, discomfort, and overall impression of the devices

\begin{tabular}{|c|c|c|c|c|c|c|c|}
\hline \multirow[t]{2}{*}{ Assessment } & \multirow[t]{2}{*}{ Category } & \multicolumn{3}{|l|}{ Autoinjector } & \multicolumn{3}{|c|}{ Prefilled syringe } \\
\hline & & $\begin{array}{l}\text { Autoinjector } \\
\text { first }\end{array}$ & $\begin{array}{l}\text { Prefilled } \\
\text { syringe first }\end{array}$ & Overall & $\begin{array}{l}\text { Autoinjector } \\
\text { first }\end{array}$ & $\begin{array}{l}\text { Prefilled } \\
\text { syringe first }\end{array}$ & Overall \\
\hline \multirow{5}{*}{$\begin{array}{l}\text { Ease of use of } \\
\text { self-injection }\end{array}$} & Extremely easy & $27(60.0)$ & $26(56.5)$ & $53(58.2)$ & $9(20.0)$ & $15(32.6)$ & $24(26.4)$ \\
\hline & Easy & $17(37.8)$ & $16(34.8)$ & $33(36.3)$ & $20(44.4)$ & $23(50.0)$ & $43(47.3)$ \\
\hline & Neither easy nor difficult & I (2.2) & I (2.2) & $2(2.2)$ & II (24.4) & $5(10.9)$ & $16(17.6)$ \\
\hline & Difficult & $0(0.0)$ & $\mathrm{I}(2.2)$ & $I(I . I)$ & $2(4.4)$ & $\mathrm{I}(2.2)$ & $3(3.3)$ \\
\hline & Extremely difficult & $0(0.0)$ & $2(4.3)$ & $2(2.2)$ & $3(6.7)$ & $2(4.3)$ & $5(5.5)$ \\
\hline \multirow{5}{*}{$\begin{array}{l}\text { Discomfort } \\
\text { during self- } \\
\text { injection }\end{array}$} & No discomfort & $27(60.0)$ & $29(63.0)$ & $56(61.5)$ & II (24.4) & $24(52.2)$ & $35(38.5)$ \\
\hline & Mild discomfort & $17(37.8)$ & $13(28.3)$ & $30(33.0)$ & $20(44.4)$ & $17(37.0)$ & $37(40.7)$ \\
\hline & Moderate discomfort & I (2.2) & $4(8.7)$ & $5(5.5)$ & $9(20.0)$ & $2(4.3)$ & II (I2.I) \\
\hline & Severe discomfort & $0(0.0)$ & $0(0.0)$ & $0(0.0)$ & $3(6.7)$ & $0(0.0)$ & $3(3.3)$ \\
\hline & $\begin{array}{l}\text { Such discomfort that I } \\
\text { cannot inject future doses }\end{array}$ & $0(0.0)$ & $0(0.0)$ & $0(0.0)$ & $2(4.4)$ & $3(6.5)$ & $5(5.5)$ \\
\hline \multirow{5}{*}{$\begin{array}{l}\text { Overall } \\
\text { impression } \\
\text { of the self- } \\
\text { injection } \\
\text { experience }\end{array}$} & Extremely favorable & $17(37.8)$ & $26(56.5)$ & $43(47.3)$ & $8(I 7.8)$ & $18(39.1)$ & $26(28.6)$ \\
\hline & Favorable & $25(55.6)$ & $13(28.3)$ & $38(41.8)$ & $19(42.2)$ & $21(45.7)$ & $40(44.0)$ \\
\hline & $\begin{array}{l}\text { Neither favorable nor } \\
\text { unfavorable }\end{array}$ & $3(6.7)$ & $5(10.9)$ & $8(8.8)$ & $13(28.9)$ & $4(8.7)$ & $17(18.7)$ \\
\hline & Unfavorable & $0(0.0)$ & $2(4.3)$ & $2(2.2)$ & $3(6.7)$ & I (2.2) & $4(4.4)$ \\
\hline & Extremely unfavorable & $0(0.0)$ & $0(0.0)$ & $0(0.0)$ & $2(4.4)$ & $2(4.3)$ & $4(4.4)$ \\
\hline
\end{tabular}

Note: Data presented as n (\%).

favorable impression of the prefilled syringe. An unfavorable impression of the device or worse was reported by only 2 patients $(2.2 \%)$ when using the autoinjector but by 8 patients $(8.8 \%)$ when using the prefilled syringe.

The order of use of the 2 different devices appeared to slightly bias the subjects toward the device they used first. For example, the proportion of patients with an extremely favorable or favorable impression of the autoinjector was $93.3 \%$ when it was used first vs $84.8 \%$ when it was used second. Likewise, the proportion of patients with an extremely favorable or favorable impression of the prefilled syringe was $84.8 \%$ when it was used first vs $60.0 \%$ when it was used second.

\section{Safety}

None of the patients experienced a serious adverse event. Treatment-emergent adverse events, all mild or moderate in severity, were reported by 10 patients (10.1\%) (Table S3). These events included injection-site hematoma $(n=2)$, injection-site pain $(n=1)$, palpitations $(n=1)$, UC flare $(n=1)$, dyspepsia $(n=1)$, flatulence $(n=1)$, hemorrhoidal hemorrhage $(n=1)$, tooth sensitivity $(n=1)$, parotid gland enlargement $(n=1)$, viral upper respiratory tract infection $(n=1)$, headache $(n=1)$, and hot flush $(n=1)$.

\section{Discussion}

This study showed that most patients with moderate-tosevere UC preferred to self-administer golimumab with the autoinjector over a prefilled syringe. More patients found the autoinjector easier to use and to less often cause discomfort than the prefilled syringe. This preference for the autoinjector did not change when measured again 2 weeks later, during which time most delayed reactions would have appeared. Demographic characteristics did not significantly affect preference. Order of presentation did not affect the overall preference for the autoinjector, although it biased the preference somewhat toward the device first presented. The results of this study are strengthened by the fact that data were collected in a real-life clinical setting at multiple sites. In addition, although the absolute sample size was small, this study included a relatively large population for UC and was enough to observe meaningful differences in preference.

Overall opinions were also favorable in the GO-MORE trial, in which patients with active RA self-injected or had someone else administer subcutaneous golimumab with the same device. ${ }^{4}$ Although individuals with RA often suffer from hand pain, swelling, and deformities, in GO-MORE, two-thirds of patients who chose to self-inject selected the autoinjector over a prefilled syringe. Most of the patients in the GO-MORE study who used the autoinjector had a favorable impression of it, considered it easy to use, and reported that it caused little pain or discomfort. However, the study did not directly assess preference or compare patient experiences between the autoinjector and injection with the prefilled syringe. A preference for the golimumab autoinjector over previous injection devices was also reported by $70.6 \%$ of patients in the GO-SAVE trial, which included patients with active RA who were switched from adalimumab or etanercept to golimumab. ${ }^{12}$ 
Prefilled pens or other autoinjectors are also preferred over and considered easier to use and less painful than syringes for self-administration of darbepoetin by chronic kidney disease patients, ${ }^{11}$ methotrexate ${ }^{13}$ and adalimumab ${ }^{14}$ for RA patients, and insulin for diabetes patients. ${ }^{15-18}$ Similarly, a study in healthy volunteers found that subcutaneous injection by autoinjector was preferred over syringe injection by a nurse. ${ }^{19}$

A systematic review in 2013 found that treatment adherence to anti-TNF biologics in UC patients was only $52.7 \%{ }^{20}$ It also found that administration with a syringe vs a pen was a predictor of nonadherence. Although the SmartJect autoinjector might therefore be expected to improve adherence to golimumab, we did not assess adherence in this study.

\section{Conclusion}

This study showed that patients with UC generally prefer to administer golimumab with an autoinjector. Although this should help inform prescribers about what their patients may expect, they should be aware that some patients might still prefer using a prefilled syringe.

\section{Acknowledgments}

Medical writing was provided by Dr Phillip Leventhal (4Clinics, Paris, France) and funded by MSD Belgium. The work was funded by MSD. The study funder participated in designing the study; and collecting, analyzing, and interpreting the data; writing the report; and in the decision to submit it for publication.

\section{Author contributions}

$\mathrm{S}$ Vermeire participated in developing a first draft of the manuscript together with the medical writer. All authors contributed to patient recruitment, analysis and interpretation of the results, critical revision of the manuscript, and approval of the final version.

\section{Disclosure}

$\mathrm{S}$ Vermeire has received consulting fees from AbbVie, MSD, Takeda, Ferring, Genentech/Roche, Shire, Pfizer Inc, Galapagos, Mundipharma, Hospira, Celgene, Second Genome, and Janssen; research grants from AbbVie, MSD, and Takeda; and speaker fees from AbbVie, MSD, Takeda, Ferring, Dr Falk Pharma, Hospira, and Tillots. F Baert received research grants from AbbVie, Chiesi, MSD, and Ipsen, Roche; and speaker and consultancy fees from Abbvie, Hospira, Janssen (Johnson \& Johnson), MSD, Mundipharma, Falk, Ferring, and Takeda. O Dewit received research grants from Abbvie and MSD; consulting fees from Ferring, Mundipharma, Hospira, Takeda, and Janssen; and speaker fees from MSD, Ferring, Mundipharma, Hospira, and Takeda. P Van Hootegem received consultancy fees from Janssen (Johnson \& Johnson) and Takeda; and speaker fees from Falk and Ferring. D Franchimont received honorarium fee for lectures; consulting fees and/or educational grants from Amgen, Pfizer, Mundipharma, AbbVie, MSD, Takeda, Ferring, Falk, Merck Serono, Roche and Janssen. E Louis has received grants from MSD and AbbVie; speaker fees from AbbVie, Ferring, MSD, Chiesi, Mitsubishi Pharma, Hospira, Janssen, and Takeda; and is on the advisory board of AbbVie, Ferring, MSD, Takeda, Mitsubishi Pharma, Celltrion, and Prometheus. The authors report no other conflicts of interest in this work.

\section{References}

1. Cosnes J, Gower-Rousseau C, Seksik P, Cortot A. Epidemiology and natural history of inflammatory bowel diseases. Gastroenterology. 2011; 140(6):1785-1794.

2. Stange EF, Travis SP, Vermeire S, et al. European evidence-based consensus on the diagnosis and management of ulcerative colitis: definitions and diagnosis. J Crohns Colitis. 2008;2(1):1-23.

3. Gilardi D, Fiorino G, Allocca M, Bravata I, Danese S. Golimumab: clinical update on its use for ulcerative colitis. Drugs Today (Barc). 2015;51(3):171-184.

4. Schulze-Koops H, Giacomelli R, Samborski W, et al. Factors influencing the patient evaluation of injection experience with the SmartJect autoinjector in rheumatoid arthritis. Clin Exp Rheumatol. 2015; 33(2):201-208.

5. Kivitz A, Segurado OG. HUMIRA pen: a novel autoinjection device for subcutaneous injection of the fully human monoclonal antibody adalimumab. Expert Rev Med Devices. 2007;4(2):109-116.

6. Lasalvia P, Barahona-Correa JE, Romero-Alvernia DM, et al. Pen devices for insulin self-administration compared with needle and vial: systematic review of the literature and meta-analysis. J Diabetes Sci Technol. 2016;10(4):959-966.

7. Ridyard CH, Dawoud DM, Tuersley LV, Hughes DA. A systematic review of patients' perspectives on the subcutaneous route of medication administration. Patient. 2016;9(4):281-292.

8. Wong M, Abdulnabi R, Carey MA, Fu H. A randomized, cross-over comparison of preference between two reusable insulin pen devices in pen-naive adults with diabetes. Curr Med Res Opin. 2013;29(5): 465-473.

9. Pfutzner A, Schipper C, Niemeyer M, et al. Comparison of patient preference for two insulin injection pen devices in relation to patient dexterity skills. J Diabetes Sci Technol. 2012;6(4):910-916.

10. Phillips JT, Fox E, Grainger W, Tuccillo D, Liu S, Deykin A. An openlabel, multicenter study to evaluate the safe and effective use of the single-use autoinjector with an Avonex ${ }^{\circledR}$ prefilled syringe in multiple sclerosis subjects. BMC Neurol. 2011;11:126.

11. Lim WH, Chan D, Boudville N, et al. Patients' perceptions of subcutaneous delivery of darbepoetin alfa by autoinjector prefilled pen versus prefilled syringe: a randomized, crossover study. Clin Ther. 2012;34(9): 1948-1953.

12. Tandon N, Bolce R, Naim A, et al. PMS66 satisfaction with and preference for golimumab and its auto-injector among rheumatoid arthritis patients switched from adalimumab or etanercept. Value Health. 2012; 15(4):A45-A46. 
13. Demary W, Schwenke H, Rockwitz K, et al. Subcutaneously administered methotrexate for rheumatoid arthritis, by prefilled syringes versus prefilled pens: patient preference and comparison of the self-injection experience. Patient Prefer Adherence. 2014;8:1061-1071.

14. Kivitz A, Cohen S, Dowd JE, et al. Clinical assessment of pain, tolerability, and preference of an autoinjection pen versus a prefilled syringe for patient self-administration of the fully human, monoclonal antibody adalimumab: the TOUCH trial. Clin Ther. 2006;28(10):1619-1629.

15. Pfutzner A, Bailey T, Campos C, et al. Accuracy and preference assessment of prefilled insulin pen versus vial and syringe with diabetes patients, caregivers, and healthcare professionals. Curr Med Res Opin. 2013; 29(5):475-481.

16. Campos C, Lajara R, Deluzio T. Usability and preference assessment of a new prefilled insulin pen versus vial and syringe in people with diabetes, physicians and nurses. Expert Opin Pharmacother. 2012;13(13): 1837-1846.
17. Pfutzner A, Asakura T, Sommavilla B, Lee W. Insulin delivery with FlexPen: dose accuracy, patient preference and adherence. Expert Opin Drug Deliv. 2008;5(8):915-925.

18. Korytkowski M, Bell D, Jacobsen C, Suwannasari R. A multicenter, randomized, open-label, comparative, two-period crossover trial of preference, efficacy, and safety profiles of a prefilled, disposable pen and conventional vial/syringe for insulin injection in patients with type 1 or 2 diabetes mellitus. Clin Ther. 2003;25(11):2836-2848.

19. Berteau C, Schwarzenbach F, Donazzolo Y, et al. Evaluation of performance, safety, subject acceptance, and compliance of a disposable autoinjector for subcutaneous injections in healthy volunteers. Patient Prefer Adherence. 2010;4:379-388.

20. Lopez A, Billioud V, Peyrin-Biroulet C, Peyrin-Biroulet L. Adherence to anti-TNF therapy in inflammatory bowel diseases: a systematic review. Inflamm Bowel Dis. 2013;19(7):1528-1533. 


\section{Supplementary materials}

Table SI List of participating ethics committees

\author{
UZ Leuven \\ Commissie Medische Ethiek \\ Professor Minne Casteels \\ Herestraat 49 \\ B-3000 Leuven \\ Tel: $016348600 \mathrm{Fax} 016348601$ \\ Email ec-submission@uzleuven.be

\section{UZ Gent} \\ Commissie Medische Ethiek \\ Professor Dirk Matthys \\ De Pintelaan 185 \\ B-9000 Gent \\ Tel: 093323336 Fax 093324962 \\ Email ethisch.comite@ugent.be
}

\section{AZ Groeninge, Campus Loofstraat \\ Commissie Medische Ethiek \\ Dokter Peter Doubel \\ Loofstraat 43 \\ 8500 Kortrijk \\ Tel: 056635072 Fax 056635057 \\ Email ethisch.comite@azgroeninge.be}

\section{UZ Antwerpen}

Commissie Medische Ethiek

Patrick Cras

Wilrijkstraat 10

2650 Edegem

Tel: 03 82। 3544 Fax 03 82। 4254

Email ethisch.comite@uza.be

\section{CHU Sart Tilman}

Comité d'Ethique Hospitalo-Facultaire Universitaire de Liège Professeur V. Seutin

Centre Hospitalier Universitaire du Sart Tilman, B35

4000 Liège

Tel: 0436683 I0 Fax 04366744 I

Email ethique@.chu.ulg.ac.be

H Hart Ziekenhuis Roeselare - Menen vzw

\section{Commissie Medische Ethiek}

Dr. L. Harlet

Wilgenstraat 2

8800 Roeselare

Tel: 056522230 Fax 056522520

Email sdeneve@hhr.be October 2014 Page 2

Sint Augustinus (GZA Ziekenhuizen)

Commissie Medische Ethiek

Professor Bart Van den Eynden

Sint-Vincentiusstraat 20

2018 Antwerpen

Tel: 034434558 Fax 032392323

Email hilde.poulissen@gza.be
Table SI (Continued)

Zol Genk, Campus St Jan
Comité Medische Ethiek
Doctor Patrick Noyens
Schiepse Bos 6
3600 Genk
Tel: 089321602 Fax 089327900
Email ec.submission@zol.be

\section{AZ ST Jan Brugge}

Commissie Medische Ethiek

Doctor Ludo Vanopdenbossch

Ruddershove 10

8000 Brugge

Tel: 050459942 Fax 050453057

Email ethisch.comite@azsintjan.be

\section{UCL St Luc}

Commission d'Ethique Biomédicale Hospitalo-Facultaire de I'UCL

Professor J.M. Maloteaux

Avenue Hippocrate 55. 14, Tour Harvey, niveau 0

1200 Bruxelles

Tel: 0276455 I4 Fax 0276455 I3

Email commission.ethique@md.ucl.ac.be

\section{CHC St Joseph Liège}

Comité d'ethique médicale des cliniques St Joseph

Doctor René Stevens

Rue de Hesbaye 75

4000 Liège

Tel: 042248990 Fax 042298992

Email rene.stevens@chc.be

La citadelle de Liège

Comité d'ethique médicale

Professeur François DAMAS

Boulevard du I2ème de Ligne, I

4000 Liège

Tel: 042256935 Fax 04225764 l

Email marie.louise.frenay@chrcitadelle.be

OLV ziekenhuis Aalst

Ethisch Comité OLV Ziekenhuis

Doctor Antoon Leloup

Moorselbaan 164

9300 Aalst

Tel: 053724660 Fax 053724689

Emailantoon.leloup@olvz-aalst.be

\section{Hôpital Erasme \\ Comité d'Ethique}

Prof. Dr. André Herchuelz

Route de Lennik 808

1070 Bruxelles

Tel: 02-555 3707 Fax 02-555 4620

Email comite.ethique@erasme.ulb.ac.be

(Continued) 
Table SI (Continued)

\section{GHDC, Saint-Joseph, Charleroi}

Comité d'Ethique Hospitalier, Grand Hopital de Charleroi

Mrs Laurence Gillard

Grand Rue 3

6000 Charleroi

Tel: 07। I0 4330 Fax 07I I0 8596

Emailduthoy.audrey@ghdc.be

\section{ZNA Jan Palfijn Antwerpen}

Dr. P.P. De Deyn

Commissie voor Medische Ethiek ZNA

ZNA Koningin Paola Kinderziekenhuis (P6- lokaal 617)

Lindendreef I,

2020 Antwerpen

Tel: 03/280.34.29 of 03/280.34.28 Fax 03/280.30.60

Email ethische.commissie@zna.be

Centre Hospitalier de Wallonie picarde - CHwapi A.S.B.L.

\section{Site Union}

Dr. Luc Desplanque

Comité d'Ethique

39, Boulevard Lalaing

7500 Tournai

Tel: 069331756 Fax 069258654

Email luc.desplanque@chwapi.be/ nathalie.mat@.chwapi.be

October 2014 Page 4

\section{Virga Jesse ziekenhuis, Hasselt}

Dr. Koen Magerman

Ethische Toetsingscommissie Virga Jesse

Stadsomvaart II

3500 Hasselt

Tel: 0I I/30.9l.II Fax 01 I/30.9l.18

Email ethische.toetsingscommissie@virgajesse.be

CHR Peltzer La Tourelle

Dr. Hassan Kalantari

Comité d'Ethique

Rue du Parc 29

4800 Verviers

Tel: 087/2। 21 7। Fax 087/2I.2I.39

Email comite.ethique@chplt.be

\section{AZ Sint Maarten}

Dr. J. Vander Sande

Ethisch comité van vzw Emmaüs

Edgard Tinellaan Ic

2800 Mechelen

Tel: 0I5/44 67 2I Fax 0154467 I0

Email brigitte.van.looy@emmaus.be

AZ Damiaan

Dr. Guy Fonteyn

Ethisch Comité

Gouwelozestraat 100

8400 Oostende

Tel: 0504 I 4067 Fax 0504 | 4078

Email mbrusselle@azdamiaan.be
Table SI (Continued)

AZ St Lucas

Dr. Rob Schildermans

Ethische Commissie

AZ St Lucas Brugge

Sint-Lucaslaan 29

8310 Brugge

Tel: +325036569l Fax +3250365695

Email nancy.vanavermaete@stlucas.be

Table S2 Patient demographic characteristics

\begin{tabular}{|c|c|}
\hline Characteristic & Value \\
\hline Number included in the per-protocol analysis & 91 \\
\hline \multicolumn{2}{|l|}{ Age (years) } \\
\hline Mean (SD) & $42.7(14.4)$ \\
\hline Range & 19.7-93.7 \\
\hline \multicolumn{2}{|l|}{ Sex, n (\%) } \\
\hline Male & $54(59.3)$ \\
\hline Female & $37(40.7)$ \\
\hline \multicolumn{2}{|l|}{ Ethnicity, n (\%) } \\
\hline White/Caucasian & $89(97.8)$ \\
\hline Other & $2(2.2)$ \\
\hline \multicolumn{2}{|l|}{ Marital status, n (\%) } \\
\hline Single & $23(25.3)$ \\
\hline Married/living together & $67(73.6)$ \\
\hline Widow & $\mathrm{I}(\mathrm{I} . \mathrm{I})$ \\
\hline \multicolumn{2}{|l|}{ Highest education level, $n$ (\%) } \\
\hline Primary education & $6(6.6)$ \\
\hline Vocational secondary education & $13(14.3)$ \\
\hline Technical secondary education & $13(14.3)$ \\
\hline General secondary education - humanities & $12(13.2)$ \\
\hline Higher education (graduate/nonuniversity) & $30(33.0)$ \\
\hline Higher education (university) & $17(18.7)$ \\
\hline \multicolumn{2}{|l|}{ Professional status, n (\%) } \\
\hline Student & $9(9.9)$ \\
\hline Working full time & $48(52.7)$ \\
\hline Working part time & II (I2.I) \\
\hline Not working & $23(25.3)$ \\
\hline \multicolumn{2}{|l|}{ Time since UC diagnosis $(y)$} \\
\hline Mean (SD) & $8.6(8.8)$ \\
\hline Range & $0.0-38.1$ \\
\hline \multicolumn{2}{|c|}{ Most frequent concomitant conditions ( $\geq 3 \%), \mathrm{n}(\%)$} \\
\hline Arthritis & $4(4.4)$ \\
\hline Arthralgia & $4(4.4)$ \\
\hline Psoriasis & $3(3.3)$ \\
\hline Primary sclerosing cholangitis & $3(3.3)$ \\
\hline Other & $6(6.6)$ \\
\hline \multicolumn{2}{|l|}{ Previous exposure to anti-TNF, n (\%) } \\
\hline Naive & $76(83.5)$ \\
\hline Experienced & $15(16.5)$ \\
\hline \multicolumn{2}{|l|}{ Concomitant medications, n (\%) } \\
\hline 5-Aminosalicylic acid & $68(74.7)$ \\
\hline Corticosteroids & $59(64.8)$ \\
\hline Azathioprine & $37(40.7)$ \\
\hline Other & $2(2.2)$ \\
\hline
\end{tabular}


Table S2 (Continued)

\begin{tabular}{|c|c|}
\hline Characteristic & Value \\
\hline \multicolumn{2}{|l|}{ Total Mayo score } \\
\hline Mean (SD) & $8.8(1.6)$ \\
\hline Min, $\max$ & 6,12 \\
\hline \multicolumn{2}{|l|}{ Total Mayo score categories, n (\%) } \\
\hline 6 & $7(7.9)$ \\
\hline $7-9$ & $49(55.1)$ \\
\hline$\geq 10$ & $33(37.1)$ \\
\hline \multicolumn{2}{|l|}{ Stool frequency, n (\%) } \\
\hline Normal & $0(0.0)$ \\
\hline I-2 stools more than normal & $6(6.7)$ \\
\hline $3-4$ stools more than normal & $4 I(45.6)$ \\
\hline 5 or more stools more than normal & $43(47.8)$ \\
\hline \multicolumn{2}{|l|}{ Rectal bleeding, n (\%) } \\
\hline No blood seen & $6(6.7)$ \\
\hline Streaks of blood with stools less than half the time & $27(30.0)$ \\
\hline Obvious blood with stool most of the time & $37(4 I .1)$ \\
\hline Blood alone passed & $20(22.2)$ \\
\hline \multicolumn{2}{|l|}{ Physician's global assessment, n (\%) } \\
\hline Normal & $0(0.0)$ \\
\hline Mild disease & $4(4.4)$ \\
\hline Moderate disease & $65(72.2)$ \\
\hline Severe disease & $21(23.3)$ \\
\hline \multicolumn{2}{|l|}{ Sigmoidoscopic/endoscopic findings, n (\%) } \\
\hline Normal or inactive disease & $0(0.0)$ \\
\hline Mild disease & I (I.I) \\
\hline Moderate disease & $54(60.7)$ \\
\hline Severe disease & $34(38.2)$ \\
\hline
\end{tabular}

Abbreviations: UC, ulcerative colitis; TNF, tumor necrosis factor.

Table S3 Treatment-emergent adverse events

\begin{tabular}{|c|c|c|c|c|c|c|}
\hline Adverse event & Severity & Patients & $\begin{array}{l}\text { Onset } \\
\text { (time after } \\
\text { injections) }\end{array}$ & $\begin{array}{l}\text { Potentially } \\
\text { related }\end{array}$ & $\begin{array}{l}\text { Action } \\
\text { taken }\end{array}$ & $\begin{array}{l}\text { Resolution } \\
\text { (time after } \\
\text { onset) }\end{array}$ \\
\hline \multirow[t]{2}{*}{ Injection-site hematoma } & Mild & $\mathrm{I}$ & I day & Yes & None & 6 days \\
\hline & Mild & 1 & 2 days & No & None & 12 days \\
\hline Injection-site pain & Mild & I & 6 days & Yes & None & Ongoing \\
\hline Palpitations & Mild & $\mathrm{I}$ & 3 days & No & None & I day \\
\hline Flatulence & Moderate & I & 6 days & No & None & 3 months \\
\hline Dyspepsia & Mild & 1 & 10 days & No & Medication & 3 months \\
\hline UC flare & Moderate & I & I day & Yes & Medication & 2 months \\
\hline Viral upper respiratory tract infection & Mild & I & I day & Yes & None & \\
\hline Headache & Mild & 1 & 3 days & Yes & Medication & Ongoing \\
\hline Hot flushes & Mild & I & I day & Yes & None & Ongoing \\
\hline Hemorrhoidal hemorrhage & Mild & $\mathrm{I}$ & 9 days & No & None & Ongoing \\
\hline Tooth sensitivity & Mild & I & 6 days & Yes & None & Ongoing \\
\hline Parotid gland enlargement & Mild & I & 12 days & No & Echography & I month \\
\hline
\end{tabular}

Abbreviation: UC, ulcerative colitis.

\section{Publish your work in this journal}

Patient Preference and Adherence is an international, peer-reviewed, open access journal that focuses on the growing importance of patient preference and adherence throughout the therapeutic continuum. Patient satisfaction, acceptability, quality of life, compliance, persistence and their role in developing new therapeutic modalities and compounds to optimize clinical outcomes for existing disease states are major areas of interest for the journal. This journal has been accepted for indexing on PubMed Central. The manuscript management system is completely online and includes a very quick and fair peer-review system, which is all easy to use. Visit http://www. dovepress.com/testimonials.php to read real quotes from published authors. 